\title{
Retraction Note: GIS-based marine atmospheric environment and fishery company governance structure
}

\author{
Xu Ding ${ }^{1}$
}

Published online: 25 November 2021

C) Saudi Society for Geosciences 2021

\section{Retraction Note: Arabian Journal of Geosciences (2021) 14: 1510}

https://doi.org/10.1007/s12517-021-07713-z

The Editor-in-Chief and the Publisher have retracted this article because the content of this article is nonsensical. The peer review process was not carried out in accordance with the Publisher's peer review policy. The author disagrees with this retraction.

The original article can be found online at https://doi.org/10.1007/ s12517-021-07713-z.

Xu Ding

kendihg@163.com

1 School of Economics and Management, Chongqing Jiaotong University, Chongqing 400074, China 